\title{
MODELAÇÃO DO CONSUMO DE CLORO NA OXIDAÇÃO DE MATÉRIA ORGÂNICA PRESENTE EM ÁGUAS SUPERFICIAIS COM DIFERENTES ORIGENS (PORTUGAL E ANGOLA)
}

\author{
R. J. E. MARTINS ${ }^{1,2}$ e R. A. R. BOAVENTURA ${ }^{2}$ \\ ${ }^{1}$ Instituto Politécnico de Bragança, Escola Superior de Tecnologia e de Gestão, Departamento de \\ Tecnologia Química e Biológica \\ ${ }^{2}$ Universidade do Porto, Laboratory of Separation and Reaction Engineering (LSRE), Departamento \\ de Engenharia Química \\ E-mail para contato: rmartins@ipb.pt
}

\begin{abstract}
RESUMO - A qualidade da água para consumo humano é uma condição indispensável na sociedade atual. Entre os requisitos de qualidade de uma água de referir a isenção de contaminação bacteriológica, o que requer um processo de desinfeção, normalmente por cloragem, como etapa final do processo de tratamento. Na operação de cloragem é consumido cloro por oxidação de compostos orgânicos presentes na água. Neste trabalho, foi estudado o consumo de cloro pela água bruta do Rio Bengo (Angola) e da água à saída da ETA de Lever (Portugal). Em particular, estudou-se a cinética do decaimento do cloro no seio de amostras de água, tendo sido realizados vários ensaios distribuídos por duas séries: $1^{\text {a }}$ ) variou-se a concentração de cloro, mantendo constante o teor de matéria orgânica (expressa como oxidabilidade ao $\mathrm{KMnO}_{4}$ ), à temperatura de $25^{\circ} \mathrm{C}$ e $35^{\circ} \mathrm{C}$, e na $2^{\mathrm{a}}$ ) foi mantida a concentração de cloro e fez-se variar a oxidabilidade. Foram ajustados diferentes modelos cinéticos aos resultados experimentais de decaimento de cloro e de matéria orgânica; o modelo de primeira ordem paralela foi o que descreveu de forma mais satisfatória a cinética de consumo do cloro.
\end{abstract}

\section{INTRODUÇÃO}

A água é elemento fundamental para todo e qualquer tipo de vida, com especial relevância para o homem, sendo indispensável num amplo e diversificado leque de atividades humanas, com destaque para o abastecimento público e industrial, atividades agrícolas, produção de energia elétrica e as atividades de lazer e recreio, bem como aquelas associadas à preservação da vida aquática (Alves, 2007).

Com a evolução da qualidade de vida das populações foi-se desenvolvendo uma maior preocupação com os bens essenciais. A água passou de um recurso considerado praticamente inesgotável para uma parte significativa do globo, num bem de preservação fundamental. Tal mudança de mentalidade acarretou uma preocupação com a qualidade da água. As fontes ou origens 


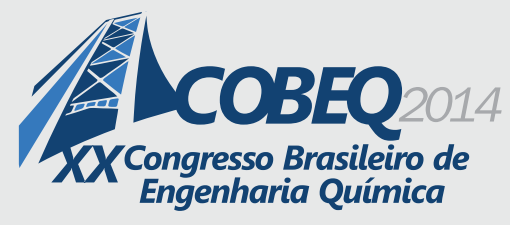

19 a 22 de outubro de 2014

Florianópolis/SC

de água atuais alteraram-se face às de há algumas décadas atrás, sendo que o progressivo desenvolvimento industrial e as práticas agrícolas conduziram a uma alteração significativa dos parâmetros de qualidade da água. Por ex.:, o aumento da atividade agrícola desenvolvida na proximidade de mananciais tem originado preocupação relativamente a uma possível contaminação por pesticidas. Sabe-se que a agricultura é uma das fontes possíveis de contaminação ambiental, geralmente apontada como importante contribuinte de poluentes (Grutzmacher et al., 2008).

Em Angola, existem vários rios e nascentes que constituem origens de água para abastecimento de água para consumo humano em diferentes cidades do país. Na Capital, dois rios principais fornecem água à cidade, o Rio Bengo, cuja água é tratada na Estacão de Tratamento de Kifangondo, situada no nordeste da Capital, no Município de Cacuaco e o Rio Kwanza, em que a água é tratada na Estação de Tratamento de Kikuxi, situada a sudeste de Luanda, em Viana. Relativamente a Portugal o estudo centrou-se no Rio Douro, nomeadamente na água à saída da ETA de Lever (Águas do Douro e Paiva, SA), que abastece entre outros, os municípios do Porto e Vila Nova de Gaia.

A água deve satisfazer alguns requisitos de qualidade para ser consumida. Em particular, a ausência de qualquer contaminação bacteriológica, o que requer uma desinfeção da água, sendo o processo mais usual a cloragem, como etapa final do processo de tratamento. Na operação de cloragem é consumido cloro por oxidação de compostos orgânicos presentes na água, a que acresce o consumo por reação ao longo do sistema de distribuição.

A pré-oxidação de águas superficiais com cloro ou hipoclorito de sódio é um dos processos utilizados nas Estações de Tratamento de Água (ETA) para melhorar o desempenho dos processos de tratamento subsequentes, em particular, o processo de coagulação/floculação química (Filho, 2001).

O cloro adicionado vai sendo consumido por reações químicas com substâncias naturais de origem orgânica, na sua maioria substâncias húmicas e fúlvicas resultantes da ação bacteriológica nas lenhites e taninos dos organismos vegetais, sendo os ácidos húmicos mais reativos que os fúlvicos, levando a uma diminuição da sua concentração inicial. Destas reações resultam subprodutos de oxidação, como principal destaque para os trihalometanos (clorofórmio, diclorobromometano, clorodibromometano e bromofórmio) prejudiciais à saúde, que é necessário quantificar e controlar (Paschoalato et al., 2008; EPA, 2011).

É importante, por isso, conhecer a velocidade de consumo do cloro nas águas superficiais submetidas a pré-oxidação (Filho, 2001; Paschoalato et al., 2008) para dimensionamento dos tanques de pré cloragem e cálculo da dosagem de cloro a aplicar. A velocidade de consumo depende da composição da água, da concentração inicial de cloro, da temperatura e, eventualmente, de outros fatores. A partir de resultados experimentais obtidos em laboratório é possível selecionar, de entre vários modelos geralmente aplicáveis ao decaimento do cloro (Gang et al., 2003), aquele que modele adequadamente a evolução da concentração de cloro e possa ser utilizado, conhecidos os parâmetros cinéticos, no dimensionamento de uma unidade de pré-cloragem.

O teor da matéria orgânica na água já tratada por coagulação/floculação química é, contudo, bastante baixo, o que dificulta o estudo cinético do consumo de cloro. No entanto, o cloro é muitas 
vezes utilizado numa etapa inicial de pré-oxidação direta da água bruta superficial.

O objetivo principal deste estudo foi estudar a cinética de decaimento do cloro no seio de amostras de água de diferentes proveniências - Rio Bengo (Angola) e à saída da ETA de Lever (Portugal). Como objetivos específicos são de referir: (1) ajuste de diferentes modelos cinéticos aos resultados experimentais do decaimento do cloro no seio de água; (2) comparar os modelos e selecionar o mais adequado; (3) avaliar a influência da temperatura sobre os parâmetros cinéticos.

\section{MATERIAIS E MÉTODOS}

\subsection{Amostras}

A água superficial usada neste estudo foi recolhida no Rio Bengo, próximo da ETA de Kifangondo, Luanda-Angola, e transportada para o Laboratório de Engenharia da Separação, Reacção Química e Ambiente da Universidade Agostinho Neto (LESRA) em garrafões de 5 L, onde se realizaram os ensaios experimentais. No laboratório as amostras foram conservadas no frigorifico a $4^{\circ} \mathrm{C}$, até à realização das experiências laboratoriais. Para os ensaios em Portugal, as amostras foram colhidas à saída da ETA de Lever, antes da desinfeção final (cloragem), seguindo procedimento idêntico ao anteriormente descrito.

\subsection{Métodos Analíticos e Reagentes}

O cloro residual nas amostras de água foi determinado pelo método DPD (titulação com sulfato ferroso amoniacal) de acordo com o Standard Methods for The Examination of Water and Wastewater (APHA, 2012).

A quantidade de matéria orgânica presente nas amostras de água bruta foi expressa em termos de oxidabilidade ao $\mathrm{KMnO}_{4}$. Usou-se o método volumétrico de oxidação-redução, em que o oxigénio equivalente à matéria orgânica foi medido pelo consumo de um agente oxidante (permanganato de potássio).

A solução stock de hipoclorito de sódio usada nos ensaios foi preparada a partir de lixívia contendo 5,25\% de $\mathrm{NaOCl}$, obtendo-se uma concentração final de $64,3 \mathrm{mg} \mathrm{Cl} / \mathrm{L}$.

As soluções de sulfato ferroso amoniacal (FAS), solução tampão fosfato, e solução indicadora de DPD (N,N-dietil-p-fenilenediamina) foram preparadas de acordo com a descrição no Standard Methods (APHA, 2012).

\subsection{Modelos de Decaimento do Cloro}

$\mathrm{Na}$ última década diversos estudos têm abordado o consumo de cloro em águas superficiais e potáveis, tendo sido propostos vários modelos para descrever o decaimento do cloro (Gang, 2003; Hua et al., 1999; Kastl et al., 1999; Beleza, 2005). A modelação do decaimento representa a evolução, espacial e temporal, da concentração de cloro, associada ao transporte físico desta espécie, bem como 
a reações químicas que ocorrem com outras espécies em solução.

Para este estudo foram selecionados os seguintes modelos:

a) Modelo de pseudo segunda ordem

$$
C=C_{0} /\left(1+C_{0} \cdot K \cdot t\right)
$$

b) Modelo de primeira ordem limitada

$$
C=C^{*}+\left(C_{0}-C^{*}\right) \cdot e^{-k t}
$$

c) Modelo de primeira ordem paralela

$$
C=C_{0} \cdot x \cdot e^{-k_{1} t}+C_{0} \cdot(1-x) \cdot e^{-k_{2} t}
$$

\subsection{Procedimento Experimental}

O decaimento do cloro devido a reações que ocorrem no seio da água foi estudado através do designado "teste de garrafa", que permite avaliar unicamente o efeito das reações que ocorrem no seio da água. Em frascos de Winkler foi introduzida água com concentrações de cloro inicial conhecidas, sendo realizadas medições de cloro a intervalos de tempo previamente definidos, de forma a permitir uma avaliação da cinética das reações.

Numa primeira experiência fez-se variar a concentração inicial de cloro mantendo constante a concentração inicial de matéria orgânica. A segunda experiência consistiu num conjunto de ensaios com a concentração inicial de cloro constante e fazendo variar a concentração inicial de matéria orgânica. Todos os ensaios foram realizados em duplicado, e para dois valores de temperatura, 25 e $35^{\circ} \mathrm{C}$. A metodologia adoptada para os "testes de garrafa" foi adaptada de Vieira et al. (2002).

\section{RESULTADOS E DISCUSSÃO}

\subsection{Concentração Inicial de Cloro Variável $\left(0,65\right.$ - 4,7 $\left.\mathrm{mg} \mathrm{Cl}_{2} / \mathrm{L}\right)$ e Temperatura de $25^{\circ} \mathrm{C}$}

Foram realizados quatro ensaios à temperatura de $25^{\circ} \mathrm{C}$, para concentrações iniciais de cloro na gama 0,65 a $4,7 \mathrm{mg} \mathrm{Cl}_{2} / \mathrm{L}$, mantendo constante a concentração inicial de matéria orgânica (oxidabilidade inicial de 4,6 $\mathrm{mg}_{2} / \mathrm{L}$ ), para estudo do decaimento do cloro residual no seio da água do Rio Bengo ao longo do tempo. Na Tabela 1 podem ser visualizados os resultados experimentais obtidos para os tempos pré-determinados. Para os ensaios realizados com água da ETA de Lever apenas serão apresentadas algumas conclusões.

O intuito deste ensaios é determinar as constantes cinéticas de decaimento do cloro no seio da água, e consequentemente prever de forma satisfatória a velocidade com que ocorrem as reações entre o cloro e a matéria orgânica presente na água bruta. 
Tabela 1 - Concentração de cloro residual em função do tempo para valores de concentração inicial de cloro no intervalo 0,65 a 4,7 $\mathrm{mgCl}_{2} / \mathrm{L}$ (oxidabilidade inicial de $4,6 \mathrm{mg} \mathrm{O}_{2} / \mathrm{L} ; \mathrm{T}=25^{\circ} \mathrm{C}$ )

\begin{tabular}{cccccc}
\hline Tempo (min) & \multicolumn{4}{c}{$\mathrm{C}\left(\mathrm{mg} \mathrm{Cl}_{2} / \mathrm{L}\right)$} \\
\hline & $\mathrm{CH}$ & $\mathrm{C}_{0}=0,65$ & $\mathrm{C}_{0}=1,3$ & $\mathrm{C}_{0}=2,7$ & $\mathrm{C}_{0}=4,7$ \\
0 & & 0,65 & 7,6 & 7,5 & 7,6 \\
3 & & 0,20 & 0,60 & 2,7 & 4,7 \\
6 & & 0,15 & 0,40 & 1,55 & 2,9 \\
9 & & 0,05 & 0,30 & 1,25 & 2,4 \\
12 & & 0,02 & 0,25 & 1,20 & 2,1 \\
15 & & 0,02 & 0,20 & 1,20 & 2,05 \\
20 & 0,02 & 0,15 & 1,10 & 1,95 \\
\hline
\end{tabular}

Os modelos em avaliação neste estudo (pseudo primeira ordem, primeira ordem limitada e primeira ordem paralela) foram ajustados aos dados experimentais usando o software de optimização não linear KaleidaGraph versão 4.1.3 da Synergy. Nas Tabelas 2 a 4 encontram-se os valores obtidos para os parâmetros de cada modelo cinético, e ainda os parâmetros estatísticos coeficiente de correlação do ajuste $\left(\mathrm{R}^{2}\right)$ e variância estimada $\left(\mathrm{S}^{2}\right)$.

Tabela 2 - Parâmetros do modelo de pseudo segunda ordem

\begin{tabular}{cccc}
\hline $\mathrm{C}_{0}\left(\mathrm{mg} \mathrm{Cl}_{2} / \mathrm{L}\right)$ & $\mathrm{K} \pm \mathrm{SE}$ & $\mathrm{R}^{2}$ & $\mathrm{~S}^{2}$ \\
\hline 0,65 & $1,284 \pm 0,199$ & 0,986 & $2,15 \mathrm{xE}^{-2}$ \\
1,3 & $0,289 \pm 0,004$ & 0,999 & $8,99 \mathrm{xE}^{-2}$ \\
2,7 & $0,0429 \pm 0,0069$ & 0,874 & 0,307 \\
4,7 & $0,0248 \pm 0,004$ & 0,895 & 0,932 \\
\hline
\end{tabular}

Tabela 3 - Parâmetros do modelo de primeira ordem limitada

\begin{tabular}{ccccc}
\hline $\mathrm{C}_{0}\left(\mathrm{mg} \mathrm{Cl}_{2} / \mathrm{L}\right)$ & $\mathrm{C}^{*} \pm \mathrm{SE}$ & $\mathrm{k} \pm \mathrm{SE}$ & \multicolumn{1}{c}{$\mathrm{R}^{2}$} & \multicolumn{1}{c}{$\mathrm{S}^{2}$} \\
\hline 0,65 & $0,025 \pm 0,017$ & $0,365 \pm 0,049$ & 0,986 & $2,87 \mathrm{xE}^{-2}$ \\
1,3 & $0,194 \pm 0,058$ & $0,302 \pm 0,026$ & 0,994 & $9,52 \mathrm{xE}^{-2}$ \\
2,7 & $1,191 \pm 0,138$ & $0,393 \pm 0,073$ & 0,975 & 0,164 \\
4,7 & $2,035 \pm 0,086$ & $0,354 \pm 0,021$ & 0,997 & 0,528 \\
\hline
\end{tabular}

Uma avaliação dos resultados experimentais (Tabela 1) permite concluir, como era esperado, que ocorre uma diminuição do cloro residual livre com o decorrer do tempo, devido a reações de oxidação com as espécies químicas presentes na água, e consequente formação de subprodutos de desinfeção. 
Tabela 4 - Parâmetros do modelo de primeira ordem paralela

\begin{tabular}{cccccl}
\hline $\mathrm{C}_{0}\left(\mathrm{mg} \mathrm{Cl}_{2} / \mathrm{L}\right)$ & $\mathrm{x}$ & $\mathrm{k}_{1}$ & $\mathrm{k}_{2}$ & \multicolumn{1}{c}{$\mathrm{R}^{2}$} & \multicolumn{1}{c}{$\mathrm{S}^{2}$} \\
\hline 0,65 & 0,57 & 0,191 & $1,000 *$ & 0,997 & $2,65 \mathrm{xE}^{-2}$ \\
1,3 & 0,41 & 0,064 & 0,514 & 0,999 & $8,93 \times \mathrm{xE}^{-2}$ \\
2,7 & 0,59 & 0,019 & 0,926 & 0,995 & 0,140 \\
4,7 & 0,50 & 0,009 & 0,444 & 0,999 & 0,505 \\
\hline
\end{tabular}

* sem significado estatístico

O período máximo definido para os ensaios revelou-se adequado, já que ao fim de 20 minutos os resultados mostram concentrações de cloro residual livre que tendem para um valor aproximadamente constante. Resultado similar foi registado para as amostras da ETA de Lever; em que partindo duma concentração inicial de cloro de $0,64 \mathrm{mg} / \mathrm{L}(\mathrm{COT}=4,53 \mathrm{mg} / \mathrm{L})$, decorridos 20 minutos o decaimento de cloro foi de aproximadamente $80 \%$.

Uma análise aos parâmetros e respetivos erro padrão mostra que existe um único ensaio (Tabela $\left.4 ; \mathrm{C}_{0}=0,65 \mathrm{mg} / \mathrm{L}\right)$, em que um parâmetro $\left(\mathrm{k}_{2}\right)$ é estatisticamente não significativo.

$\mathrm{Na}$ Figura 1 (a-d) podem ser visualizados os resultados experimentais para as quatro concentrações iniciais de cloro estudadas e os modelos cinéticos de decaimento do cloro na água.

A análise dos coeficientes de correlação evidencia que é o modelo de primeira ordem paralela que melhor descreve a cinética de decaimento do cloro no seio da água do Rio Bengo, para concentração inicial constante de matéria orgânica. Este exibe duas fases distintas, uma primeira fase em que as reações são mais rápidas e uma segunda fase caracterizada por uma menor velocidade das reações. O primeiro grupo de reações inclui a reação de espécies mais reativas como a amónia e alguns compostos orgânicos, e o segundo a reação com espécies menos reativas (aminas e compostos orgânicos pouco reativos).

Para o estudo realizado em Portugal $\left(\mathrm{C}_{0}\right.$ na gama 0,51 a $\left.2,01 \mathrm{mg} \mathrm{Cl}_{2} / \mathrm{L}\right)$ os resultados mostraram igualmente que o decaimento de cloro no seio da água é bem descrito pelo modelo de primeira ordem paralela (coeficientes de correlação, $\mathrm{R}^{2}$, superiores a 0,99 ).

Contudo, uma análise estatística mais detalhada permitirá tirar conclusões adicionais sobre a qualidade dos ajustes, recorrendo a um Teste- $F$, expresso como o quociente das variâncias de dois modelos em comparação (Martins, 2004).

Para o presente estudo e adotando uma significância de 5\% temos $F_{C}(6: 6)=4,28$. Este teste permite avaliar se um dado modelo cinético é mais preciso que outro e, em segundo lugar, se existe uma diferença estatisticamente significativa na previsão dos dois modelos. 
(a) $\mathrm{C} 0=0.65 \mathrm{mg} / \mathrm{L}$

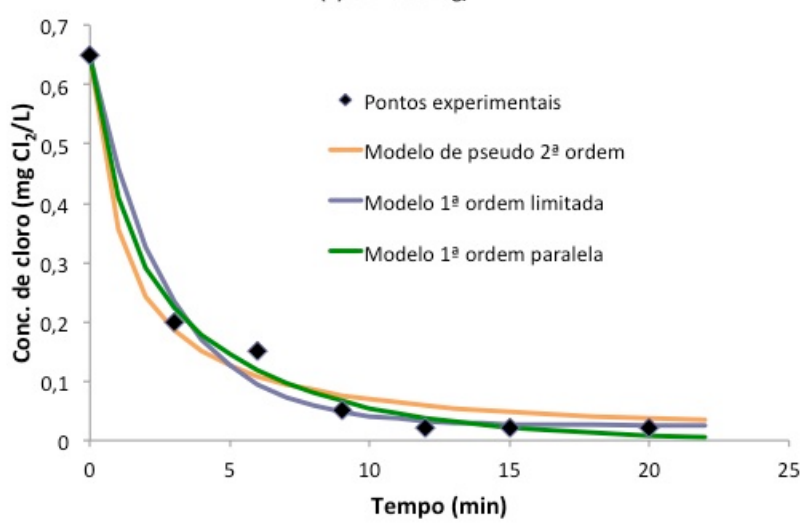

(c) $\mathrm{C} 0=2,7 \mathrm{mg} / \mathrm{L}$

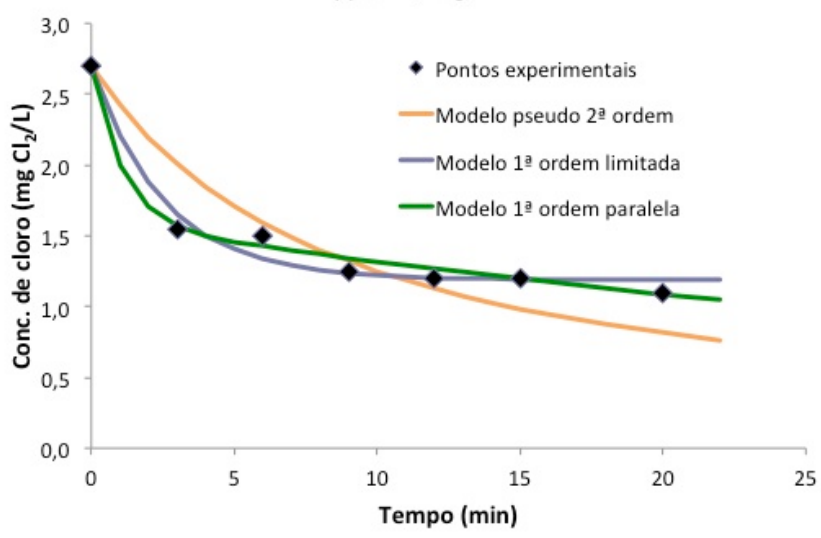

(b) $\mathrm{C} 0=1,3 \mathrm{mg} / \mathrm{L}$

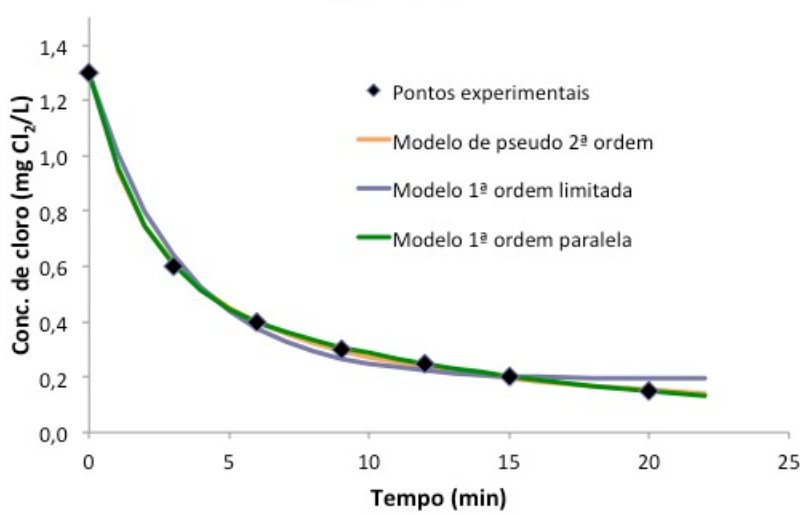

(d) $\mathrm{C} 0=4,7 \mathrm{mg} / \mathrm{L}$

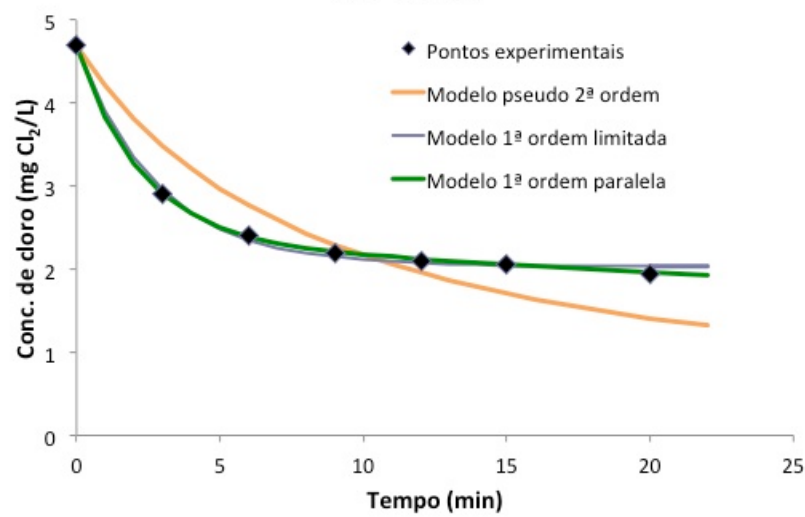

Figura 1 - Cinética de decaimento de cloro a $\mathrm{T}=25^{\circ} \mathrm{C}$ : (a) $\mathrm{C}_{0}=0,65 \mathrm{mg} \mathrm{Cl} / \mathrm{L}$; (b) $\mathrm{C}_{0}=1,3 \mathrm{mg}$ $\mathrm{Cl}_{2} / \mathrm{L}$; (c) $\mathrm{C}_{0}=2,7 \mathrm{mg} \mathrm{Cl}_{2} / \mathrm{L}$; (d) $\mathrm{C}_{0}=4,7 \mathrm{mg} \mathrm{Cl}_{2} / \mathrm{L}$.

Na Tabela 5 apresentam-se os valores de F obtidos na comparação dos três modelos: modelo de pseudo $2^{\mathrm{a}}$ ordem (P2); modelo de $1^{\mathrm{a}}$ ordem limitada (PL); modelo $1^{\mathrm{a}}$ ordem paralela (PP).

Tabela 5 -Teste F para um nível de confiança de 95\% aplicado ao decaimento do cloro na água; graus de liberdade $6: 6 ; \mathrm{F}_{\text {crítico }}=4,28$

\begin{tabular}{cccc}
\hline $\mathrm{C}_{0}$ & \multicolumn{3}{c}{$\mathrm{F}$ calculado } \\
\hline & $\mathrm{PL} / \mathrm{P} 2$ & $\mathrm{PP} / \mathrm{P} 2$ & $\mathrm{PL} / \mathrm{PP}$ \\
0,65 & 1,33 & 1,23 & 1,08 \\
1,3 & 1,06 & 0,99 & 1,07 \\
2,7 & 0,53 & 0,46 & 1,17 \\
4,7 & 0,57 & 0,54 & 1,05 \\
\hline
\end{tabular}

Com exceção do ensaio para $\mathrm{C}_{0}=0,65 \mathrm{mg} / \mathrm{L}$, em que foram obtidos valores sem significado estatístico para alguns dos parâmetros do modelo PP, o modelo de $1^{\mathrm{a}}$ ordem paralelo foi o que ajustou 
melhor os dados experimentais (Fcalculado $>1$ ), o que confirma as conclusões anteriores a partir dos valores de $\mathrm{R}^{2}$. Contudo, os dados da Tabela 5 mostram que não é significativa a precisão obtida por este modelo (PP), para uma probabilidade de 95\%, em relação aos modelos PL e P2 (Fcalculado < 4,28).

\section{CONCLUSÕES}

O cloro decai na água, fruto de reações que podem ocorrer no seio da água.

A reação do cloro no seio da água é caracterizada por duas fases: uma rápida e uma segunda mais lenta. O primeiro grupo de reações inclui a reação de espécies mais reativas como a amónia e alguns compostos orgânicos, e no segundo a reação de espécies menos reativas como determinados compostos orgânicos e aminas.

Para os dois estudos - água do Rio Bengo e da ETA de Lever, o modelo de primeira ordem paralela representa bem a cinética de consumo do cloro, para a gama de concentração inicial de cloro estudada e concentração de matéria orgânica inicial constante, considerando as duas fases que caracterizam a reação do cloro na água.

A análise estatística efetuada para o estudo em Angola, permite concluir que não é estatisticamente significativa a precisão do modelo de primeira ordem paralela, para uma probabilidade de $95 \%$, relativamente aos modelos de pseudo $2^{\mathrm{a}}$ ordem e de $1^{\mathrm{a}}$ ordem limitada.

\section{NOMENCLATURA}

Concentração de cloro num instante $\mathrm{t}$

[mg.L]

$\mathrm{C}_{0} \quad$ Concentração inicial de cloro

[mg.L]

C*

Fração de cloro residual inicial que não reage

[mg.L]

$\mathrm{k}$

Constante cinética de decaimento

$\left[\mathrm{min}^{-1}\right]$

$\mathrm{k}_{1}$

Constante de velocidade

$\left[\min ^{-1}\right]$

$\mathrm{k}_{2} \quad$ Constante de velocidade

$\left[\min ^{-1}\right]$

$\mathrm{K}$

Constante cinética de decaimento

$\left[\mathrm{L} \cdot \mathrm{mg}^{-1} \cdot \mathrm{min}^{-1}\right]$

$\mathrm{X}$

Componente do cloro residual

[ - ]

\section{REFERÊNCIAS}

ALVES, C. Tratamento de águas de abastecimento. Porto: Publindústria, Edições Técnicas, 2007. 


\section{9 a 22 de outubro de 2014}

Florianópolis/SC

APHA. Standard Methods for the Examination of Water and Wastewater. Washington DC: 22 Ed., 2012.

BELEZA, J. M. B. Simulação das concentrações de cloro residual e trihalometanos em redes de distribuição de água para consumo humano. Porto: Dissertação de Mestrado, FEUP, 2005.

Environmental Protection Agency. Joint position statement trihalomethanes in drinking water november 2011. Health Service Executive, 2011.

HUA, F.; WEST, J. R.; BARKER, R. A.; FORSTER, C. F. Modelling of chlorine decay in municipal water supplies. Wat. Res., v. 33(12), p. 2735-2746, 1999.

FILHO, S. S. F. Remoção de compostos orgânicos precursores de subprodutos da desinfeção e seu impacto na formação de trihalometanos em águas de abastecimento. Revista de Engenharia Sanitária e Ambiental, v. 6(1), p. 53- 60, 2001.

GANG, D. C.; CLEVENGER, T. E.; BANERJI, S. K. Modeling chlorine decay in surface water. J. of Environ. Informatics, v. 1(1), p. 21-27, 2003.

GRUTZMACHER, D. D.; GRUTZMACHER, A. D.; AGOSTINETTO, D.; LOECK, A. E.; ROMAN, R.; PEIXOTO, S. C.; ZANELLA, R. Monitoramento de agrotóxicos em dois mananciais hídricos no sul do Brasil. Revista Brasileira de Engenharia Agricola e Ambiental, v. 12(6), p. 632$637,2008$.

KASTL, G. J.; FISHER, I. H.; JEGATHEESAN, V. Evaluation of the chlorine decay kinetics expressions for drinking water systems modelling. Aqua, v. 48(6), p. 219-227, 1999.

MARTINS, R. J. E. Acumulação e libertação de metais pesados por briófitas aquáticas. Porto: Tese de doutoramento, FEUP, 2004.

PASCHOALATO, C. F.; TRIMAILOVAS, M. R.; Bernardo, L. D. Formação de subprodutos orgânicos halogenados nas operações de pré-oxidação com cloro, ozone e peroxónio e pós-cloração em água contendo substância húmica. Revista de Engenharia Sanitária e Ambiental, v. 13(3), p. 313322, 2008.

VIEIRA, P.; COELHO, S. T.; PRAÇA, P. Modelação do cloro residual como instrumento de controlo da qualidade da água em sistemas de abastecimento. $6^{\circ}$ Congresso da Água, Porto, 2002. 